\title{
EXERCISE LEVELS AND RESTING PULSE RATE IN THE COMMUNITY
}

\section{G. D. LAIRD and M. J. CAMPBELL}

Department of Medical Statistics and Computing, The University of Southampton

\section{ABSTRACT}

A community survey examined attitudes to exercise in relation to health, measured levels of exercise participation, and related exercise participation to resting pulse rate. A questionnaire was sent to $\mathbf{4 0 0}$ Southampton residents selected by a systematic random sample from the electoral roll, and provided 259 useful responses, yielding an effective response rate of $68 \%$, with an average age of 46 years. Attitudes to health benefits of exercise were generally very positive; $92 \%$ thought that exercise was important for staying in good health. Attitudes were less positive in subjects over 50 years old, and in social classes IV and V.

Although $35 \%$ had done some vigorous exercise during the last four weeks only $7 \%$ of social classes IV and V had done so. A total of $22(8.5 \%)$ had exercised for at least 20 minutes, 3 or more times per week, and $17(77 \%)$ of these were males with an average age of 29 years.

Ninety per cent of the sample were able to take their own resting heart rate. Resting heart rate was 7 beat.min-1 lower in subjects who exercised for at least 20 minutes 3 or more times per week than the average.

Key words: Community survey, Exercise levels, Resting pulse rate, Attitudes to exercise

\section{INTRODUCTION}

We are constantly being urged to 'look after your heart", and a recurrent theme in health education programmes is to take more exercise. The Lilleshall Hall Symposium on exercise, health and medicine concluded that "The role of exercise in protection against coronary heart disease is now sufficiently established for it to be assimilated into routine public health and health education practice" (Sports Council, 1984). American public health policy now recommends that all adults should participate in exercise vigorous enough to reach $60 \%$ of maximal oxygen uptake for at least $\mathbf{2 0}$ minutes three times a week (Powell et al, 1986). This level of exercise is sufficient to produce a cardiovascular training effect. However, it can be very difficult to persuade people to change their lifestyle. Providing people with the facts is rarely sufficient, as is evidenced by the failure of many anti-smoking campaigns. What is needed is a variety of approaches to persuade people to take up exercise. These campaigns will need to be evaluated and for this methods of measuring the amount of exercise people take need to be defined and methods of measuring the validity of assessment must be established.

It is difficult to measure accurately the nature and intensity of leisure exercise (Taylor et al, 1978). It would be useful to have an objective measure of exercise level. Garcia-Palmieri et al (1982) in a study of physical activity and ischaemic heart disease incidence in Puerto Rico, found that, amongst those they measured, the variable most strongly correlated with exercise level was resting heart rate. Sallis et al (1986) found that resting heart rate correlated well with vigorous exercise level and, in a longitudinal study, that resting heart rate was the only physiological variable that changed significantly in subjects who gave up vigorous exercise compared with those who maintained it. These authors took resting heart rate to be a validation of reported vigorous exercise level. Kannel et al (1985) have argued that the use of physiologic effects of

Address for correspondence:

Dr. M. J. Campbell

Medical Statistics and Computing

Level B

South Block

Southampton General Hospital

Southampton

SO9 4XY exercise as surrogates for exercise questionnaires is useful, and may provide more objective and reliable measures of physical activity than a questionnaire alone. Resting heart rate has also been shown to be a predictor of ischaemic heart disease development (Garcia-Palmieri et al, 1982).

On an individual basis resting heart rate is influenced by a large number of factors such as anxiety, recent alcohol consumption and environmental temperature. However, these are likely to be random effects, which will be reduced in large samples and, as the previously quoted literature has shown, resting heart rate is a useful correlate of levels of exercise in populations.

To evaluate a community response to an exercise campaign one must almost always use self-reported rather than observer-based measures of performance and fitness, and to measure changes in levels, not just absolute levels. It would be a major undertaking to use observer-based physiological measures such as maximal oxygen uptake in a large population. Campbell (1985) established that selfreported resting heart rate was a statistically significant (albeit relatively poor) predictor of running speed during a half marathon, and Khosla and Campbell (1982) found significant differences in mean resting heart rate between fast, medium and slow finishers to a marathon. These authors ended by stating that the importance of resting heart rate as an indicator of health and of risk of disease had been neglected in earlier epidemiological studies and that it deserved more respect and attention.

Thus the purpose of the present study is: (i) to describe levels of vigorous exercise taking in a community and study attitudes towards exercise taking; (ii) to evaluate the practicality of measuring resting heart rate (RHR) in a community study of exercise; and (iii) to examine the relationship between resting pulse rate and reported vigorous exercise.

\section{METHODS}

\section{Resting heart rate pilot study}

To examine the repeatability and validity of the resting pulse rate measurement, a small pilot study was performed. Twelve people measured their resting heart rate on three separate days, at roughly the same time of day on each occasion. As broad a cross-section as possible of age, sex and social class was chosen. On a separate occasion, these 
twelve measured their own heart rate and it was then measured by one of the authors (GDL) using manual palpation.

\section{HOW TO MEASURE YOUR RESTING HEART RATE}

Please try and measure your resting heart rate in the following way. The best time to do this is after your evening meal after you have been sitting down for about five minutes. Place the tips of your index and middle fingers lightly over a point on your left wrist about 1.5 inches below the base of your thumb (see diagram). At this point you should be able to feel the pulsation of an artery under your skin. If not, move your fingers slightly or press harder until you can. Once you have found the right place count the number of pulsations during one minute using the second hand of your watch or a clock.

Heart Rate

beats/min

Did you find measuring your heart rate

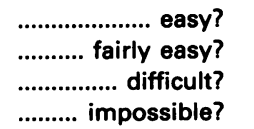

Please

Thank you very much for your help!

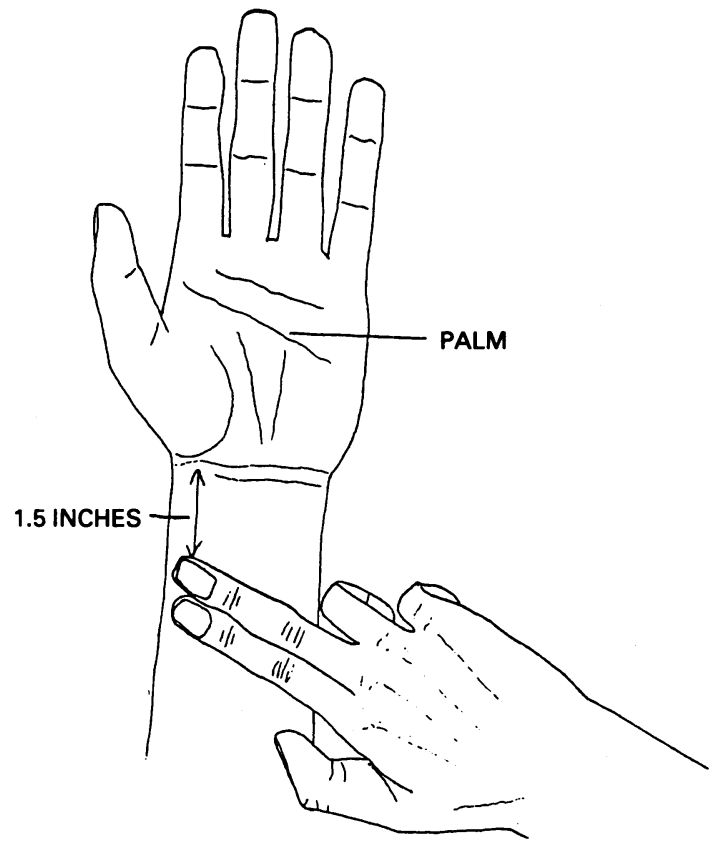

\section{Questionnaire}

A questionnaire, with a stamped addressed reply envelope, was sent to 400 Southampton residents selected by a 1:500 systematic sample of the electoral roll, with a random starting point. The questionnaire (see Appendix) elicited demographic information, attitudes to the health benefits of exercise, estimates of exercise levels at work and during leisure, and personal and environmental factors that may influence exercise levels. Vigorous exercise was defined by the activities listed in Question 15 and was restricted to activities taken in the last 4 weeks. The subjects were asked whether or not they smoked, and they were also asked to note any medication they were taking. A final question asked the respondent to measure his/her own resting heart rate according to a simple protocol (see Appendix).

\section{RESULTS}

\section{Pilot study on resting heart rate}

Six men and six women, age range 21-90 yr, took part in the study. Ten found measuring their resting heart rate (RHR) to be easy. The within subject coefficient of variation was $5.7 \%$. On the one occasion when an observer was present,

\section{APPENDIX - QUESTIONNAIRE}

\section{Attitudes to exercise}

Subjects had to reply 'strongly agree', 'agree', 'uncertain', 'disagree' or 'strongly disagree' to the following questions.

1) Exercise is important for staying in good health.

2) People who exercise regularly live longer than people that don't exercise.

3) Exercise is useful for keeping a person's weight down.

4) Regular vigorous exercise increases the risk of having a heart attack.

5) Remaining active can help to keep people fit in old age.

6) Leisure time exercise e.g. walking, gardening or sport is a good way of releasing tension.

7) The dangers of taking up exercise in later life are greater than the possible benefits.

8) Regular exercise makes people feel better.

9) It is more important to take exercise than to give up smoking.

Occupation

10) What is your occupation? (Please be as specific as possible. If you are unemployed write this down with your last job. If you are retired write this down with your occupation before you retired. If you are a housewife write this down.)

11) How much of your time at work do you spend sitting? $25 \%$ or less, $50 \%$ or less, over $50 \%$,

12) What is the best description of your job? (Mainly sedentary e.g. Office job, light activity e.g. shop assistant, moderate activity e.g. postman, heavy manual e.g. construction worker.)

Medical conditions

13) If you have any medical condition which limits the amount of exercise you are capable of please describe it briefly.

14) If you take any pills or tablets for a medical condition please write their names down.

\section{Activity}

15) Please go through the following energetic activities and fill in for any that you regularly participate in, with the number of times you participated during the last four weeks and the average length of time spent on each occasion. (Jogging; swimming; tennis, squash or badminton; aerobics, judo or martial arts; active team sports e.g. rugby hockey; heavy outdoor work e.g. digging, sawing.) If you regularly take part in any activity not listed above that is equally energetic please enter it below.

the mean self-measured RHR was 68.2 beat.min-1, and the mean observer measured rate was 68.8 (difference $0.6,95 \%$ $\mathrm{Cl},-1.5$ to 2.7 beat. $\left.\mathrm{min}^{-1}\right)$. The correlation coefficient between self-measured and observed was 0.81 . Thus selfmeasured RHR appears to be repeatable and correlates reasonably with an observer measured RHR.

\section{Questionnaire study}

Out of 400 questionnaires 259 useful responses were obtained, and 18 were returned 'not known', giving an effective response rate of $67.8 \%$. There were 135 males $(52.1 \%)$ and 124 females, and the mean age was 46.3 years (range 17 to 91). Male and female smokers comprised $32.5 \%$ and $25 \%$ respectively. This compares reasonably well with $38 \%$ and $33 \%$ in the 1982 General Household Survey. The social class distribution was close to that given by the OPCS for Southampton (OPCS, 1981).

\section{Attitudes to exercise}

The attitudes to exercise were, in general, very positive. A total of $92 \%$ agreed with the statement "exercise is important for staying in good health"; $87 \%$ believed that "exercise is useful in keeping a person's weight down". 
$88 \%$ believed that regular exercise makes people feel better and $95 \%$ believed that remaining active can help keep people fit in old age. Areas of uncertainty occurred when assessing the risks of vigorous exercise. In reply to the question "vigorous exercise increases the risk of having a heart attack", the proportion who replied (agree, uncertain, disagree) was $22 \%, 41 \%, 37 \%$ respectively. However, $47 \%$ of those aged under 50 disagreed with this statement, compared with only $27 \%$ of those 50 or over. In reply to "the dangers of taking up exercise in later life are greater than the possible benefits", the proportions (agree, uncertain, disagree) were $36 \%, 40 \%, 25 \%$; and to "it is more important to take up exercise than give up smoking", the proportions were $25 \%, 25 \%, 50 \%$. $35 \%$ of smokers agreed with this statement compared with only $21 \%$ of nonsmokers $\left(\chi^{2}=4.9\right.$, df $\left.=1, P=0.03\right)$. Surprisingly, the proportions of people who thought they took too little exercise, compared with those who thought they took enough or too much, were equal.

\section{Participation in vigorous exercise}

Fig. 1 shows the percentage of people who did any leisure vigorous activity in the last month by age. There is a clear drop in the participation rate with age and although the fall looks less steep in women, there are insufficient numbers to show a significant difference $\left(\chi^{2}=1.0, \mathrm{df}=1, \mathrm{p}=0.30\right)$.

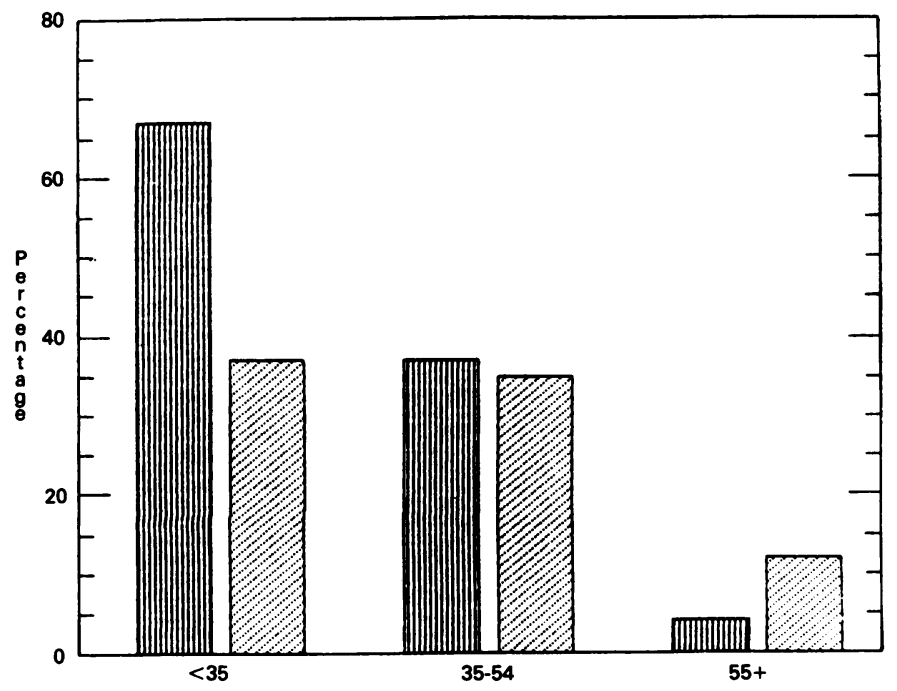

Age Group

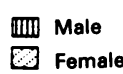

Fig. 1: Percentage who took vigorous exercise in the last month, by age group.

Fig. 2 shows the percentage of people by social class who did leisure vigorous exercise in the last month. Two sets of results are shown; the first ignores the amount of activity at work and the second counts heavy manual work as vigorous activity. Subjects who could not be classified, such as housewives and students, were assumed not to do any heavy manual work. There was a highly significant difference in social class distribution, either ignoring manual work $\left(\chi^{2}=21.6, \mathrm{df}=3, \mathrm{p}<0.001\right)$, or including it $\left(\chi^{2}=13.8\right.$, df $\left.=3, p<0.01\right)$, with social classes IV and V taking less vigorous exercise than classes I-III. Only $22(8 \%)$ of the population exercised at the recommended level of three times per week, and of these only $3(14 \%)$ were women.

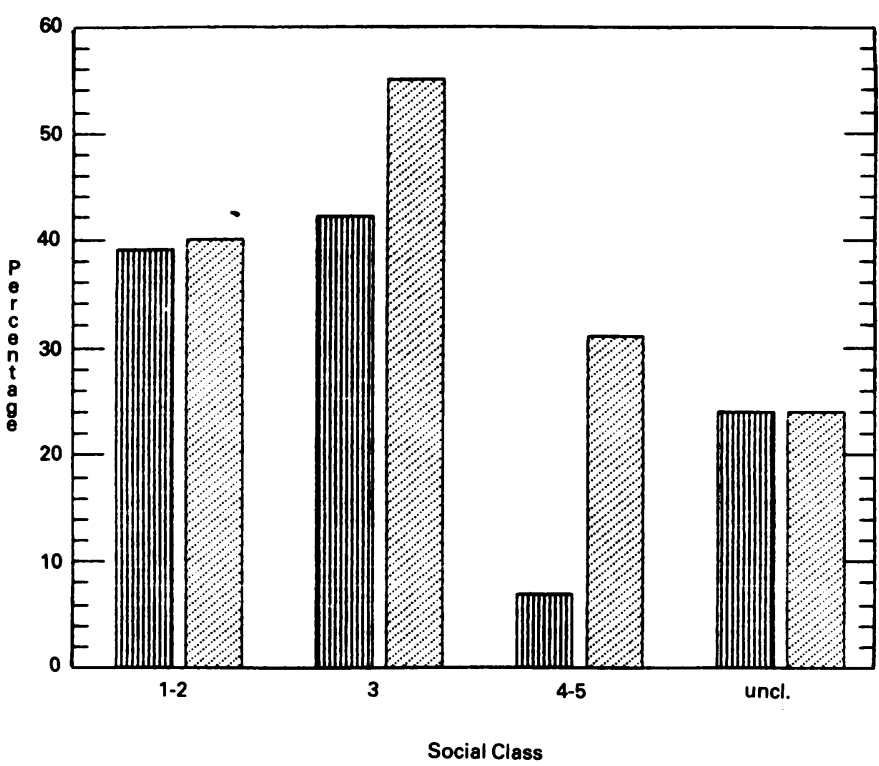

IIIII) Excluding Manual Work

2 Including Manual Work

Fig. 2: Percentage who took vigorous exercise at least once per month, by social class, including and excluding heavy manual work.

\section{Resting heart rate (RHR)}

A total of $234(90 \%)$ of respondents were able to measure their RHR, and of these $195(75 \%)$ found it either easy or fairly easy to take. Only $69 \%$ of women found it easy or fairly easy, compared with $76 \%$ of men $\left(x^{2}=5.8, \mathrm{df}=1\right.$, $p=0.16)$; and for those over $50,70 \%$ found it easy or fairly easy, compared with $84 \%$ in those under $50\left(x^{2}=6.7\right.$, df $=1$, $p=0.01)$. There were no significant differences in mean RHR between those who found it 'difficult' and those who found it 'easy' or 'fairly easy'. Table I gives some demographic characteristics of RHR; 10 respondents taking Betablocker drugs were eliminated from the analyses. Men had significantly lower RHR's than women; non-smokers had a non-significantly lower RHR than smokers; and there was no evidence of a significant relationship with age or body mass index.

\section{TABLE}

Demographic characteristics of Resting Heart Rate (RHR)

\begin{tabular}{|c|c|c|c|c|c|c|c|}
\hline & $n$ & $\begin{array}{c}\text { Mean RHR } \\
\text { (beat.min-1) }\end{array}$ & SD & Difference & $\mathrm{t}$ & $\begin{array}{c}\text { Signif- } \\
\text { icance } \\
\text { p }\end{array}$ & $95 \% \mathrm{Cl}$ \\
\hline Men & 120 & 68.7 & 10.2 & \multirow{2}{*}{2.8} & \multirow{2}{*}{1.96} & \multirow{2}{*}{0.05} & \multirow{2}{*}{$\begin{array}{lll}0.0 & -5.6\end{array}$} \\
\hline Women & 96 & 71.5 & 10.8 & & & & \\
\hline $\begin{array}{l}\text { Non-smokers } \\
\text { Smokers }\end{array}$ & $\begin{array}{r}151 \\
65\end{array}$ & $\begin{array}{l}69.3 \\
71.6\end{array}$ & $\begin{array}{l}10.5 \\
10.4\end{array}$ & 2.2 & 1.68 & 0.14 & $-0.7 \quad-5.3$ \\
\hline BMI* (kg.m-2) & & & & \multirow{3}{*}{0.3} & \multirow[b]{2}{*}{0.04} & \multirow[b]{2}{*}{0.34} & \multirow[b]{2}{*}{$-0.32-0.92$} \\
\hline $\begin{array}{l}26 \text { or less } \\
26^{*}\end{array}$ & $\begin{array}{r}173 \\
41\end{array}$ & $\begin{array}{l}70.1 \\
70.4\end{array}$ & $\begin{array}{r}10.9 \\
9.8\end{array}$ & & & & \\
\hline Age (slope) & & -0.01 & 0.03 & & 0.23 & 0.8 & $-0.06-0.07$ \\
\hline
\end{tabular}

*Body Mass Index $=(\mathrm{Wt}$ in $\mathrm{Kg}) /(\text { Height in metres })^{2}$

Table II gives the mean RHR by amount of vigorous exercise taken per week. There were significantly more missing RHR values in those who took no exercise. There was a significant difference in the level of RHR by number of times vigorous activity is taken per week, with evidence that vigorous exercise only affected resting heart rate when taken at least 3 times per week. Too few women took 
TABLE \|

Vigorous leisure activity per week and Resting Hoart Rate (beat.min-1)

\begin{tabular}{ccccc}
\hline Times per week & men & $n$ & Women & $n$ \\
\hline 0 & 69.9 & $73(12)^{*}$ & 72.0 & $60(23)^{*}$ \\
1 & 66.0 & $7(3)$ & 69.2 & $10(1)$ \\
$1-1.9$ & 70.4 & 17 & 72.1 & $15(2)$ \\
$2-2.9$ & 73.0 & $6(0)$ & 67.8 & $8(0)$ \\
3 & 61.7 & $17(0)$ & 71.7 & $3(2)$ \\
Total & 68.7 & $120(15)$ & 71.5 & $96(28)$ \\
\hline
\end{tabular}

* Missing RHR values

Overall test for differences in mean level by times per week

$F_{4,210}=2.35 p=0.05$

vigorous exercise at least 3 times per week to examine whether the effect was restricted to men.

Table III gives the mean RHR by average amount of time taken for each episode, and appears to show that subjects who exercise between 30 and 60 minutes per session apparently have lower RHR's than those of more than 60 minutes, although the results fail to reach statistical significance. For those subjects who did vigorous exercise there was no apparent relationship between the number of times per week and the average time per session per week. Of those who took vigorous exercise at least 3 times per week, $32 \%$ took on average less than $\mathbf{3 0}$ minutes per session, $32 \%$ between 30 and 60 minutes, and $36 \%$ more than an hour per session.

TABLE III

Average time of each exercise session and Resting Heart Rate (beat.min-1)

\begin{tabular}{ccccc}
\hline $\begin{array}{c}\text { Average time } \\
\text { (mins) }\end{array}$ & Men & $n$ & Women & $n$ \\
\hline 0 & 69.9 & $73(12)^{*}$ & 72.3 & $60(23)^{*}$ \\
-30 & 69.1 & $8(1)$ & 73.0 & $8(1)$ \\
$30-60$ & 65.9 & $16(1)$ & 64.7 & $11(2)$ \\
$60^{*}$ & 67.2 & $23(1)$ & 72.6 & $17(2)$ \\
\hline
\end{tabular}

* Missing RHR values

Overall test for differences in mean level by average time

$F_{3,211}=2.06 \mathrm{p}=0.1$

Table IV shows that RHR appears to be unrelated to amount of activity at work.

TABLE IV

Exercise at work and Resting Heart Rate (beat.min-1)

\begin{tabular}{llllr}
\hline & Men & $n$ & Women & $n$ \\
\hline "Mainly sedentary" & 66.7 & 28 & 73.3 & 12 \\
"Light activity" & 66.8 & 12 & 71.5 & 17 \\
"Moderate activity" & 69.5 & 17 & 68.6 & 17 \\
"Heavy manual" & 68.6 & 35 & 84.0 & 3 \\
\hline
\end{tabular}

* See definition in questionnaire

Overall test for differences in mean level per group

$F_{3,208}=0.31 p>0.1$

\section{DISCUSSION}

Previous studies of levels of exercise in the community (Taylor et al, 1978; Sallis et al, 1985; Tuxworth et al, 1986) have used trained interviewers to complete the questionnaire. This can be expensive in both time and money and so we have investigated the feasibility of a postal questionnaire. The response rate of $68 \%$ was typical for a postal questionnaire of this type sent to the general population, but it is likely that respondents interested in exercise would be more likely to reply, providing over-estimates of the amount of exercise taken in the community. In general, attitudes to the health benefits of exercise were very positive, although there were clear differences in attitude between the young and the old and between social classes, particularly towards the less readily apparent benefits of exercise, such as the protective effect of exercise on the heart. It is interesting that more smokers than non-smokers thought exercise had a greater impact on health than nonsmoking. Whether this is due to a genuine misconception on the part of smokers, or because they felt they needed to justify smoking, is impossible to tell.

Taylor et al (1978) have described the difficulties in assessing the levels of exercise in a community and validating the results. They assessed exercise levels over a complete year whereas, for example, Morris et al (1973) assessed levels for one specified weekend day and a specified week day. We chose one month as a compromise between too short a period, which would be subject to random fluctuations in exercise taking, and too long a period, where recall may be difficult. Tuxworth et al (1986) used similar criteria to those used in this study to define vigorous exercise, and found that amongst British male factory workers aged 35-60, 29\% took part in "relatively strenuous activities", comparable with our figure of $35 \%$ for the general population. The Cardiff Health Survey, from 4,294 subjects, reported $14 \%$ of subjects taking moderate or heavy exercise, 3 or more times per week, ( $N$. Vetter personal communication), which is comparable with our result of $9 \%$.

The drop off in levels of vigorous exercise with age is well reported in other studies (Sallis et al, 1985; OPCS, 1983). The dramatically lower levels of vigorous exercise in social classes IV and V fit in well with the lower sports participation found in this group by the 1983 General Household Survey (1983). Poorer attitudes to exercise, less education and lower income may all be contributing factors to this difference. Level of job exertion, which is higher in lower social classes, was not related to leisure time vigorous exercise level.

Exercise is generally perceived as a young man's domain. The message for health education is clear. To encourage further participation it should capitalise on the positive attitudes to exercise, allay the fears about possible dangers of exercise, and be targetted at the older age groups and lower social classes.

A proportion of the population perceives exercise as risky, and their fears are not entirely groundless. Even amongst habitually vigorous men, the risk of a primary cardiac arrest during exercise was five times that of the risk at other times (Siscovick et al, 1984). However, the overall risk of a primary cardiac arrest was decreased in habitually vigorous men. It is possible that, when replying to question on whether the dangers of taking up exercise in later life are greater than the possible benefits, some people were thinking of the first fact and others the second.

One American study (Taylor et al, 1978) of 179 men aged 36 to 59 found a mean resting heart rate of 66.5 beat. $\mathrm{min}^{-1}$, with a standard deviation of 10.9 beat.min-1 as measured 
by an independent observer, and these results are very close to those of Table I. The similarity of the standard deviation, and the results of the pilot study, suggest that self-measurement is of similar accuracy to observer measured pulse rate. The lower mean RHR in those exercising at levels known to produce a cardiovascular training effect supports the hypothesis that the selfreported vigorous exercise levels were valid.

The results on the average time for an episode of exercise might indicate that those with longer exercise sessions are possibly training less intensively. The fact that heavy manual exercise at work was not associated with a reduction in resting pulse rate would imply that exercise at work is of insufficient intensity to produce a training effect, a finding that has been reported elsewhere (Tuxworth et al, 1986).

Thus, in summary, we have conducted a survey of vigorous exercise taking in a community, and validated it by use of a self-measured resting heart rate. We fould selfmeasured resting heart rate to be easy to measure and repeatable and would recommend its use in community surveys of exercise taking.

\section{References}

Campbell, M. J., 1985 "Predicting running speed from a simple questionnaire". Br.J.Sports Med. 19: 142-144.

Garcia-Palmieri, M. R., Costas, R., Cruz-Vidal, M., Surlie, P. D. and Havlik, R. J.,
1982 "Increased physical activity: a protective factor against heart attacks in Puerto Rico". Am.J.Cardiol. 50: 749-755.

Kannel, W. B., Wilson, P. and Blair, S. N., 1985 "Epidemiological assessment of the role of physical activity and fitness in the development of cardiovascular disease". Am. Heart J. 109: 876-885.

Khosla, T. and Campbell, H., 1982 "Resting heart rate in marathon runners". Br.Med.J. 284: 1444.

Morris, J. N., Chave, S. P. W., Adam, C., Sivey, C., Epstein, L. and Sheehan, D. J., 1973 "Vigorous exercise in leisure-time and the incidence of coronary heart disease". Lancet i: 333-9.

Office of Population Census and Surveys, 1981. Key Statistics for urban areas: the south east, cities and towns. London, HMSO.

Office of Population Census and Surveys, 1983. General Household Survey. London, HMSO.

Powell, K. E., Krystyn, G. S., Christenson, G. M. and Mollen Kamp, M. P., 1986 "The status of the 1990 objectives for physical fitness and exercise". Public Health Reports 101: 15-21.

Sallis, S. F., Haskell, W. L., Wood, P. D., Fortmann, S. P., Rogers, T., Blair, S. N. and Paffenbarger, R. S., 1985 "Physical activity assessment methodology in the five city project". Am.J.Epidemiol. 121: 91-106.

Sallis, J. F., Haskell, W. L., Wood, P. W., Fortmann, S. P. and Vranizan, K. M. 1986 "Vigorous physical activity and cardiovascular risk factors in young adults". J.Chron.Dis. 39: 115-120.

Siscovick, D. S., Weiss, N. S., Fletcher, R. H. and Lasky, T., 1984 "The incidence of primary cardiac arrest during vigorous exercise". New England Journal of Medicine 311: 874-7.

Sports Council, Medical Research Society and Health Education Council, 1984. Exercise, Health and Medicine. London, Sports Council.

Taylor, H. L., Jacobs, D. R., Schucker, B., Knudsen, J., Leon, A. S. and Dehacker, G., 1978 "A questionnaire for the assessment of leisure time physical activities". J.Chron.Dis. 31: 741-755.

Tuxworth, W., Nevill, A. M., White, C. and Jenkins, C., 1986 "Health, fitness, physical activity and morbidity of middle aged male factory workers 1". Br.J.Indust.Med. 43: 733-753.

Title:

Authors:

\section{CARDIAC REHABILITATION: BASIC THEORY AND APPLICATION}

Publisher: $\quad$ F. A. Davis Co. UK Agents: Quest Meriden, Beckenham, 1988

Price: $\$ 33.00$ US 310 pages Tables Index References Drawings, graphs, ECGs, half-tone photos ISBN 0803611218

In the UK cardiac rehabilitation is available to only a small percentage of those who might benefit from it. Nevertheless, interest in this treatment is growing, and exercise courses for post infarct patients are now provided in about $30 \%$ of Districts. The majority of these courses have been initiated by interested nurses and physiotherapists, rather than cardiologists and physicians, and the quality of the treatment provided is unknown. There are no training courses for would-be rehabilitators in this country, and no qualification or certification available. Books cannot fill this void, but a good text would be a boon to those who wish to start, or to help, in cardiac rehabilitation programmes. There is no such publication by British authors, and these two American books are written very much for the American market.

Cardiac Rehabilitation: Basic theory and application. I do not recommend this book, little of which would be helpful to the British rehabilitator. The description of the heart and circulation gives the basic picture (including two references to the fact that the aorta is the largest artery in the body!) but unnecessarily detailed description of muscle physiology. The brief notes on exercise physiology introduce some difficult concepts, very inadequately explained, and without the use of illustrative graphs. The chapter on the physiological adaptations to training would also have been enhanced by such illustrations. The chapter on coronary disease contains a scanty description of infarction and its effects, but then includes unnecessary data about physical signs, such as gallop rhythms and mitral murmurs. The chapter on ECGs, traditional in such books, would have been better left out - the subject is much better covered elsewhere. The chapter on laboratory measurements overemphasises documentation, and uses case histories, rather than adequate description, to explain their uses: annoyingly, only trade names of drugs are given. Complicated formulae are recommended for calculating exercise prescription with unrealistic exactitude - experience teaches that exercise testing gives a guide to capacity, but that the prescription can only be confirmed by careful supervision. The actual organisation of cardiac rehabilitation programmes, which should be the meat of the book, is hardly described. Thankfully there are a few bright spots in this generally unhelpful manual - a summary of medical and surgical treatments for coronary disease, which would be a great help to paramedicals involved in rehabilitation, and a well written appendix on emergency procedures. 